OPEN ACCESS

Edited by:

Xavier Fioramonti, INRA UMR1286 Laboratoire

NutriNeuro, France

Reviewed by:

Craig Beall,

University of Exeter, United Kingdom

Luc Pénicaud

Centre National de la Recherche

Scientifique (CNRS), France

*Correspondence:

Vanessa H. Routh

routhvh@njms.rutgers.edu

${ }^{\dagger}$ Present Address:

Chunxue Zhou,

Division of Endocrinology,

Diabetes and Bone Disease,

Department of Medicine, Icahn School of Medicine at Mount Sinai, New York, NY, United States

Specialty section:

This article was submitted to Integrative Physiology, a section of the journal

Frontiers in Physiology

Received: 03 January 2018 Accepted: 23 February 2018

Published: 09 March 2018

Citation:

Zhou C, Teegala SB, Khan BA, Gonzalez C and Routh VH (2018) Hypoglycemia: Role of Hypothalamic

Glucose-Inhibited (GI) Neurons in Detection and Correction.

Front. Physiol. 9:192.

doi: 10.3389/fphys.2018.00192

\section{Hypoglycemia: Role of Hypothalamic Glucose-Inhibited (GI) Neurons in Detection and Correction}

\author{
Chunxue Zhou ${ }^{\dagger}$, Suraj B. Teegala, Bilal A. Khan, Christina Gonzalez and Vanessa H. Routh*
}

Department of Pharmacology, Physiology and Neurosciences, New Jersey Medical School, Rutgers, The State University of New Jersey, Newark, NJ, United States

Hypoglycemia is a profound threat to the brain since glucose is its primary fuel. As a result, glucose sensors are widely located in the central nervous system and periphery. In this perspective we will focus on the role of hypothalamic glucose-inhibited (Gl) neurons in sensing and correcting hypoglycemia. In particular, we will discuss Gl neurons in the ventromedial hypothalamus $(\mathrm{VMH})$ which express neuronal nitric oxide synthase (nNOS) and in the perifornical hypothalamus (PFH) which express orexin. The ability of $\mathrm{VMH}$ nNOS-Gl neurons to depolarize in low glucose closely parallels the hormonal response to hypoglycemia which stimulates gluconeogenesis. We have found that nitric oxide (NO) production in low glucose is dependent on oxidative status. In this perspective we will discuss the potential relevance of our work showing that enhancing the glutathione antioxidant system prevents hypoglycemia associated autonomic failure (HAAF) in non-diabetic rats whereas $\mathrm{VMH}$ overexpression of the thioredoxin antioxidant system restores hypoglycemia counterregulation in rats with type 1 diabetes.We will also address the potential role of the orexin-Gl neurons in the arousal response needed for hypoglycemia awareness which leads to behavioral correction (e.g., food intake, glucose administration). The potential relationship between the hypothalamic sensors and the neurocircuitry in the hindbrain and portal mesenteric vein which is critical for hypoglycemia correction will then be discussed.

Keywords: ventromedial hypothalamus, neuronal nitric oxide synthase, perifornical hypothalamus, orexin, oxidative stress, hypoglycemia associated autonomic failure, hypoglycemia unawareness

\section{INTRODUCTION}

Glucose is the primary fuel of the brain. For this reason, neural circuits exist which sense declining glucose levels and restore euglycemia. These circuits evolved to protect against falls in blood glucose during exercise or fasting. In the modern world, they are also the critical defense against life-threatening insulin-induced hypoglycemia (Cryer, 1981). When glucose levels fall below $80 \mathrm{mg} / \mathrm{dl}$ a sequential hormonal response is initiated to restore euglycemia. Insulin secretion ceases followed by the stepwise secretion of the gluconeogenic hormones glucagon, epinephrine, cortisone and growth hormone as glucose levels continue to fall toward $\sim 60 \mathrm{mg} / \mathrm{dl}$ (Amiel et al., 1988; Mitrakou et al., 1991). This hormonal response is referred to as the counterregulatory response to hypoglycemia 
(CRR). Decreasing blood glucose levels below $60 \mathrm{mg} / \mathrm{dl}$ also initiates neurogenic (e.g., palpitations, sweating) followed by neuroglycopenic (tired/drowsy, difficulty thinking) symptoms near $50 \mathrm{mg} / \mathrm{dl}$ which together comprise hypoglycemia awareness (Mitrakou et al., 1991). Hypoglycemia awareness promotes behavioral responses such as feeding or glucose administration (Cryer, 1981; Amiel et al., 1988).

Recurrent iatrogenic hypoglycemia $(\mathrm{RH})$ is the chief barrier to maintaining optimal glycemic control using intensive insulin therapy in type 1 and advanced type 2 diabetes mellitus. $\mathrm{RH}$ leads to the deleterious syndromes known as hypoglycemia associated autonomic failure (HAAF) and hypoglycemia unawareness. During HAAF, the glycemic threshold for detection of hypoglycemia shifts to lower glucose levels. When this occurs CRR initiation can be dangerously delayed and blunted in magnitude. Similarly during hypoglycemia unawareness neurogenic and neuroglycopenic symptoms do not warn an individual of impending hypoglycemia and thus prevent behavioral correction (Amiel et al., 1988; Mitrakou et al., 1991; Cryer, 2013). Hypoglycemia unawareness was thought to result from failure of autonomic activation and potentially autonomic neuropathy (Towler et al., 1993). However, more recent studies suggest that heightened arousal is necessary to recognize and interpret the peripheral neurogenic symptoms. This led to the hypothesis that incorrect interpretation of peripheral symptoms of hypoglycemia is a key component of hypoglycemia unawareness (Otlivanchik et al., 2015, 2016).

Robust initiation of corrective mechanisms is particularly important for diabetic patients since even without clinical HAAF glucagon release in response to hypoglycemia is nearly absent in type 1 and advanced type 2 diabetic patients (Bottini et al., 1997; Segel et al., 2002; Cryer, 2005; Israelian et al., 2006; Siafarikas et al., 2012; Oyer, 2013). Thus, improving and preserving proper hypoglycemia detection is critical for diabetes management. Animal studies have described glucose sensors throughout the brain and in many peripheral tissues (Routh et al., 2012). However, those within the hypothalamus have been the most extensively studied, especially in relation to HAAF and hypoglycemia unawareness (Routh, 2003; Song and Routh, 2006; Kang et al., 2008; Fioramonti et al., 2010; Chan et al., 2013; Fan et al., 2015; Otlivanchik et al., 2015, 2016). In this article we will focus on hypothalamic sensors and their involvement in these pathologies resulting from RH. We will then explore their potential interaction with the important neural circuits of the hindbrain and portal vein of the liver which are also key for the CRR (Ritter et al., 2011; Donovan and Watts, 2014).

\section{HYPOTHALAMIC GLUCOSE SENSING AND HYPOGLYCEMIA DETECTION}

Strong evidence in rodents supports a role for ventromedial hypothalamus (VMH) glucose sensors in the hormonal CRR (Borg et al., 1994, 1995, 1997; Tong et al., 2007) as well as in glucoprivic feeding (Dunn-Meynell et al., 2009). The $\mathrm{VMH}$ possesses two major subtypes of glucose-sensing neurons
(Anand et al., 1964; Oomura et al., 1964). Glucose-excited (GE) neurons increase while glucose-inhibited (GI) neurons decrease their activity as glucose levels rise (Ashford et al., 1990; Song et al., 2001). As mentioned above the ability to sense glucose has been observed throughout the brain in neurons as well as in glial cells (Levin, 2000; Marty et al., 2005; Zhou et al., 2010; Frayling et al., 2011; Melnick et al., 2011; Routh et al., 2012). It is true that any glucose sensing cell within the CNS may potentially contribute to the regulation of the CRR. However, the glucose sensitivity of $\mathrm{VMH}$ glucose sensing neurons, especially that of GI neurons, parallels the ability of the brain to sense and respond to hypoglycemia (McCrimmon et al., 2006; Song and Routh, 2006; Kang et al., 2008; Diggs-Andrews et al., 2010; Fioramonti et al., 2010, 2013). This has important implications for preserving the CRR during HAAF and diabetes. Thus, this perspective focuses primarily on these neurons. However, this does not preclude important roles for other central glucose sensors in regulating the CRR.

\section{VMH Glucose Sensing Neurons}

Like the pancreatic $\beta$-cell, glucose sensing by VMH GE neurons depends on a low-affinity hexokinase IV isoform, glucokinase (GK) and the ATP-sensitive $\mathrm{K}^{+}$channel $\left(\mathrm{K}_{\mathrm{ATP}}\right)$ (Ashford et al., 1990; Dunn-Meynell et al., 2002; Kang et al., 2006). GK also mediates glucose sensing in VMH GI neurons (DunnMeynell et al., 2002; Kang et al., 2006). However, in GI neurons, decreased glucose activates the cellular fuel sensor AMP activated protein kinase (AMPK). AMPK phosphorylates the neuronal nitric oxide (NO) synthase (nNOS) leading to NO production. NO then binds to its receptor, soluble guanylyl cyclase (sGC), which increases cyclic guanosine monophosphate (cGMP) production. Increased cGMP causes a further activation of AMPK. This cGMP mediated activation of AMPK leads to closure of a chloride channel, possibly the cystic fibrosis transmembrane regulator (CFTR), depolarization, and increased neuronal activity (Murphy et al., 2009a). These studies demonstrate that NO production is required for depolarization of GI neurons in low glucose. However, NO is a diffusible gas which acts as a retrograde signal at synapses and plays a role in plasticity (Edelmann et al., 2007; Dejanovic and Schwarz, 2014). NO diffusion also regulates neuroendocrine processes via recruitment of adjacent neurons (Bellefontaine et al., 2014). Whether NO diffusion within synapses or to adjacent cells plays a role in glucose sensing is not known.

The ability of VMH GI neurons to be activated by low glucose closely parallels the magnitude of the CRR. For example, as seen for CRR initiation, glucose levels must fall further after RH before GI neurons are activated (Song and Routh, 2006). AMPK, nNOS and sGC inhibition in the perfusion solution in vitro and in the $\mathrm{VMH}$ in vivo, respectively, blocks activation of GI neurons in low glucose and impairs the CRR (McCrimmon et al., 2008; Murphy et al., 2009a; Fioramonti et al., 2010). Hypo- or hyperglycemia induced-oxidative/nitrosative stress may underlie both the blunted response of VMH GI neurons to decreased glucose and CRR impairment (Colombani et al., 
2009; Fioramonti et al., 2013). Oxidative and nitrosative stress cause s-nitrosation of sGC (and other proteins)(Jaffrey et al., 2001). Nitrosated sGC is resistant to NO (Sayed et al., 2007). Insulin-induced hypoglycemia increases sGC s-nitrosation and $\mathrm{VMH}$ injection with a nitrosating agent impairs the CRR. Furthermore, reducing oxidative stress with the glutathione precursor, $\mathrm{N}$-acetylcysteine, in non-diabetic rats completely prevented altered glucose sensing by VMH GI neurons and CRR impairment during HAAF (Fioramonti et al., 2013). Diabetic hyperglycemia also induces oxidative stress and reduces both activation of VMH GI neurons by decreased glucose and glucagon secretion during hypoglycemia (Cryer et al., 2003; Canabal et al., 2007a; Cardoso et al., 2010; Zhou and Routh, 2017). However, N-acetylcysteine did not normalize glucose sensing and CRR initiation in diabetic animals (Zhou and Routh, 2017). Diabetic hypoglycemia is associated with impairment of the VMH thioredoxin antioxidant system via activation of the inhibitory enzyme, thioredoxin interacting protein or TXNIP (Blouet and Schwartz, 2011). VMH thioredoxin overexpression completely normalized GI neuronal glucose sensing, glycemia recovery, and glucagon secretion in rats with type 1 diabetes mellitus. However, VMH thioredoxin overexpression did not prevent HAAF in these animals (Zhou and Routh, 2017). These findings are interesting for two reasons. First, impaired glucagon secretion in diabetes is often thought to be due to local factors at the level of the alpha cell. However, these studies suggest a direct effect of the $\mathrm{VMH}$ on pancreatic alpha cell function during the CRR. Second, the effects of $\mathrm{N}$-acetylcysteine were more pronounced during $\mathrm{RH}$ whereas $\mathrm{VMH}$ thioredoxin overexpression was more effective in diabetes. Neither antioxidant system alone compensated for HAAF when it occurred during diabetes. This suggests that a combination of antioxidants might be necessary to preserve the CRR when HAAF occurs during diabetes. Figure 1 illustrated the respective roles of the $\mathrm{VMH}$ glutathione and thioredoxin systems in HAAF and diabetes.

VMH thioredoxin overexpression had 2 additional interesting and unexpected effects. First, while virtually all animals injected with the control vector developed diabetes after one injection of the $\beta$-cell toxin streptozotocin, one quarter of the $\mathrm{VMH}$ thioredoxin overexpressing animals did not (Zhou and Routh, 2017). This suggests that the VMH has a protective role on the pancreatic $\beta$-cell, perhaps by reducing inflammation. However, it should be noted that a second injection of toxin led to diabetes in the resistant animals. Nevertheless, this putative protective effect of enhanced $\mathrm{VMH}$ antioxidant defense on the pancreas deserves further study. The second unexpected effect of $\mathrm{VMH}$ thioredoxin overexpression was a reduction in the amount of insulin required to manage blood glucose levels (Zhou and Routh, 2017). Whether this is due to reduced basal hepatic glucose output, increased glucose uptake by insulin sensitive tissues, or other changes in metabolism is not known. However, this finding is consistent with a role of the $\mathrm{VMH}$ in peripheral insulin sensitivity and glucose homeostasis (Steffens et al., 1988; Martins et al., 2016; Coutinho et al., 2017). Moreover a role for $\mathrm{VMH}$ oxidative status in glucose homeostasis is consistent with a recent report that uncoupling protein regulates $\mathrm{VMH}$ glucose sensing and peripheral glycemia by decreasing oxidative stress (Toda et al., 2016).

Further support for a role of VMH GI-nNOS neurons in the CRR derives from their relationship with glutamate signaling. The VMH possesses high expression of mRNA encoding the vesicular glutamate transporter VGLUT2, a marker for glutamate neurons (Ziegler et al., 2002). Virtually all VMH nNOS neurons are glutamatergic (Chachlaki et al., 2017). Since we find that $95 \%$ of VMH GI neurons produce NO in decreased glucose and GI neurons are absent in mice lacking nNOS, it is very likely that VMH GI neurons are glutamatergic (Canabal et al., 2007b; Fioramonti et al., 2010). Mice lacking VGLUT2 selectively in steroidogenic factor 1 neurons that mark the VMH have defective CRR to insulininduced hypoglycemia (Tong et al., 2007). Taken together, these data lead us to hypothesize that maintaining normal oxidative balance in VMH glutamatergic nNOS expressing GI neurons is necessary for the CRR and potentially other aspects of glucose homeostasis.

\section{Orexin Glucose Sensing Neurons and Hypoglycemia Unawareness}

Hypothalamic orexin neurons are also GI neurons (Burdakov et al., 2005). Perifornical hypothalamus (PFH) orexin neurons play a role in epinephrine secretion during hypoglycemia (Otlivanchik et al., 2015; Korim et al., 2016). Orexin neurons may also contribute to hypoglycemia awareness. Otlivanchik et al showed that one episode of insulin-hypoglycemia in the conditioned side of a conditioned place preference (CPP) box reversed the preference for that side of the box on the subsequent day. They interpreted this finding to mean that the animal was aware of hypoglycemia, associated it with the formerly preferred side of the box and developed an aversion to that side. Interestingly, 3 consecutive daily episodes of hypoglycemia in the home cage prevented subsequent hypoglycemia on the preferred side from disrupting the CPP. This suggests that the animal exhibited hypoglycemia unawareness and thus did not develop an aversion. Interestingly, systemic injection of a brain permeant orexin antagonist mimicked hypoglycemia unawareness (Otlivanchik et al., 2016). $\mathrm{PFH}$ orexin neurons facilitate arousal via their projections to the tuberomammillary nucleus histamine neurons (Sundvik and Panula, 2015). Thus, PFH orexin-GI neurons may play a role in hypoglycemia awareness and be a target for treating hypoglycemia unawareness.

An interesting characteristic of the glucose sensitivity of $\mathrm{VMH}$ and orexin GI neurons is regulation by metabolic state. For example, fasting increases, while the satiety hormone leptin decreases the activation of VMH and orexin GI neurons, as well as that of arcuate nucleus neuropeptide Y expressing GI neurons, by decreased glucose (Murphy et al., 2009b; Sheng et al., 2014). The hunger hormone ghrelin increases the activation of orexinGI neurons in low glucose (Sheng et al., 2014). Thus, during energy deficit when low glucose is a greater threat hypoglycemia may produce a stronger activation of hypothalamic GI neurons. 


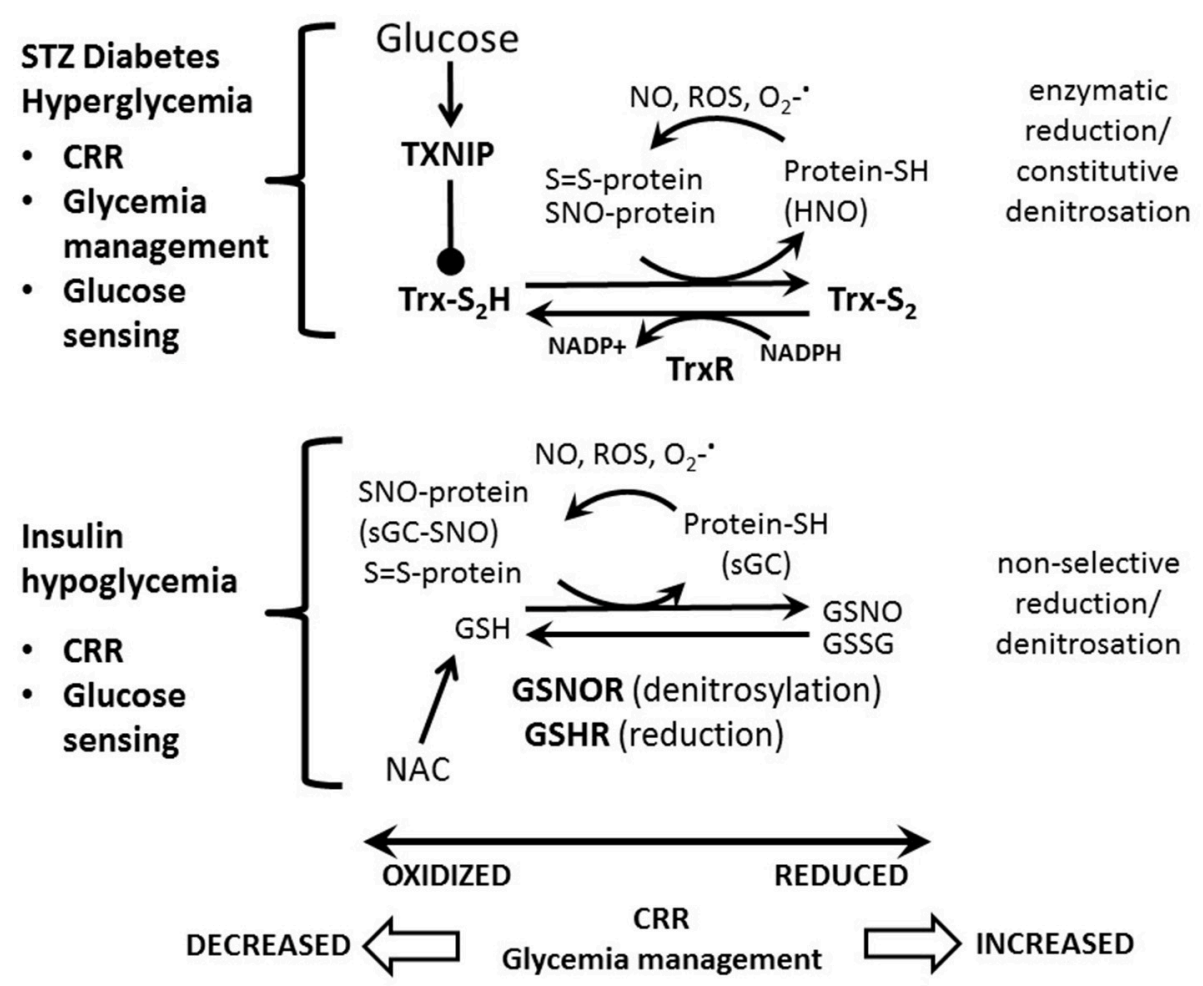

FIGURE 1 | Model for the respective roles of the VMH glutathione and thioredoxin systems in HAAF and diabetes. Increased nitric oxide (NO), reactive oxygen species (ROS) and/or superoxide $\left(\mathrm{O}_{2}^{-} \cdot\right.$ ) cause protein S-nitrosation ( $\mathrm{SNO}$-protein) and oxidation ( $\mathrm{S}=\mathrm{S}$-protein). We have shown that soluble guanylyl cyclase is $\mathrm{S}$-nitrosated (sGC-SNO) during hypoglycemia leading to impaired glucose sensing and counterregulatory response (CRR). Reduced glutathione (GSH) causes a non-selective reduction and/or denitrosation of oxidized proteins (protein-SH; SGC) becoming oxidized (GSSG) or nitrosated (GSNO) itself in the process. GSH is regenerated by the enzymes glutathione reductase (GSHR) and nitrosated glutathione reductase (GSNOR) (Nordberg and Arnér, 2001). Oral administration of the glutathione precursor, $\mathrm{N}$-acetylcysteine (NAC), completely prevents hypoglycemia associated autonomic failure (HAAF) and preserves glucose sensing by VMH GI neurons in non-diabetic but not diabetic animals. Reduced thioredoxin $\left(T r x-S_{2} H\right)$ enzymatically catalyzes protein reduction and denitrosation becoming oxidized in the process $\left(T r x-S_{2}\right)$. During denitrosation $\mathrm{HNO}$ is released. Trx- $\mathrm{S}_{2} \mathrm{H}$ is regenerated by the enzyme thioredoxin reductase (TrxR) in an NADPH dependent fashion. The glucose activated enzyme, thioredoxin interacting protein (TXNIP) reduces Trx- $\mathrm{S}_{2} \mathrm{H}$ activity (Stoyanovsky et al., 2005). VMH thioredoxin overexpression completely normalizes glucose sensing by $\mathrm{Gl}$ neurons and the CRR in diabetes alone but not when HAAF occurs during diabetes. $\mathrm{VMH}$ thioredoxin overexpression also reduces the insulin required to manage hyperglycemia in diabetes. Enzyme abbreviations are bold-faced.

This would enable a more robust response to hypoglycemia despite diminished energy reserves.

\section{RELATIONSHIP BETWEEN HYPOTHALAMIC, HINDBRAIN AND PORTAL-MESENTERIC VEIN (PMV) GLUCOSE SENSORS}

Glucose sensors in the hindbrain and PMV are critical for the CRR as detailed in several comprehensive review articles (Ritter et al., 2011; Routh et al., 2012; Donovan and Watts, 2014). Ritter and colleagues show that specific clusters of catecholamine neurons within the $\mathrm{C} 1$ cell groups $(\mathrm{C} 1 \mathrm{r}, \mathrm{C} 1 \mathrm{~m}$, $\mathrm{A} 1 / \mathrm{C} 1$ ) of the rostral ventral lateral medulla (RVLM) in rodents are essential for individual components of hypoglycemia correction including epinephrine and corticosterone secretion as well as glucoprivic feeding (Ritter et al., 1981, 1998, 2001, 2006; Li et al., 2017). The feeding and corticosterone response is mediated by forebrain projections to hypothalamus (i.e. paraventricular nucleus, $\mathrm{PFH}$ ) whereas the adrenomedullary response is mediated by bulbospinal projections (Ritter et al., 2001, 2006; Li et al., 2015b). Recent work by this group has shown that RVLM catecholamine neurons reciprocally innervate $\mathrm{PFH}$ orexin neurons in order to control glucoprivic feeding responses (Li et al., 2015a,b). These authors present the intriguing hypothesis that this interaction may enable the orexin system to coordinate arousal with feeding behavior.

Glucose sensors within the PMV are also essential for the hormonal CRR in experimental models (Donovan et al., 1994; Hevener et al., 2000; Fujita et al., 2007; Donovan and Watts, 2014). Interestingly, the role of the PMV glucose sensor in the CRR is dependent on the rate of glucose decline. That is, PMV glucose sensors dominate during slowonset hypoglycemia “ $\left(\leq 1 \mathrm{mg} / \mathrm{dL} \bullet \mathrm{min}^{-1}\right)$." In contrast, CNS sensors dominate when glucose levels fall quickly ( $\geq 2 \mathrm{mg}$. $\mathrm{dl}^{-1} \cdot \min ^{-1}$ ) (Matveyenko et al., 2007; Saberi et al., 2008; Bohland et al., 2014). The former corresponds to a drop in 
blood glucose from euglycemia $(\sim 100 \mathrm{mg} / \mathrm{dl})$ to hypoglycemia $(60 \mathrm{mg} / \mathrm{dl})$ within approximately $60 \mathrm{~min}$. while in the latter blood glucose would decrease to $60 \mathrm{mg} / \mathrm{dl}$ within $20 \mathrm{~min}$. While slower rates of decline predominate during insulin therapy in humans, rapid decline occurs at an incidence of $\sim 30 \%$ (Kovatchev et al., 2005). An additional issue to be considered when interpreting these data is that the studies of the relative role of PMV and CNS glucose sensors on the CRR were done in non-diabetic controls. Thus, whether the starting glycemia plays a role in CNS vs. peripheral detection is not known. Interestingly, hyperglycemia per se significantly reduces activation of VMH GI neurons in low glucose (Canabal et al., 2007a).

The cellular mechanism of PMV glucose sensing is still unknown. However, the effect of PMV glucose sensors on the sympathoadrenal response during slow-onset hypoglycemia is dependent on sympathetic afferents to the hindbrain (Bohland et al., 2014). Moreover, hindbrain catecholamine projections to the hypothalamus are essential for sympathoadrenal activation and glucagon secretion during slow- but not fast-onset hypoglycemia (Jokiaho et al., 2014). Together, these data suggest that an interaction between glucose sensors in the PMV and the hypothalamically projecting hindbrain catecholamine neurons is required for the secretion of epinephrine and glucagon when glucose levels fall slowly. In contrast, the hypothalamic glucose sensors dominate when glucose levels fall quickly. It is also possible that any or all of these sensors play a role in the inhibition of insulin secretion during hypoglycemia.

\section{PERSPECTIVE}

Clearly, hypoglycemia is a severe threat to the brain and therefore multiple neurocircuits have evolved to sense and restore euglycemia. The data discussed in this review suggest hierarchical control of the CRR and feeding responses to hypoglycemia. A model for such a hierarchical organization can be found in an excellent recent review (Donovan and Watts, 2014). These data also suggest some degree of specificity in control of different aspects of the response to hypoglycemia by the different glucose sensing regions. That is, slow-onset hypoglycemia is primarily sensed by the PMV and information is sequentially relayed to the hindbrain catecholamine neurons and hypothalamus in order to increase glucagon and epinephrine secretion. It is likely that this information undergoes integration and further processing at the

\section{REFERENCES}

Amiel, S. A., Sherwin, R. S., Simonson, D. C., and Tamborlane, W. V. (1988). Effect of intensive insulin therapy on glycemic thresholds for counterregulatory hormone release. Diabetes 37, 901-907. doi: 10.2337/diab.37.7.901

Anand, B. K., China, G. S., Sharma, K. N., Dua, S., and Singh, B. (1964). Activity of single neurons in the hypothalamus feeding centers: effect of glucose. Am. J. Physiol. 2207, 1146-1154.

Ashford, M. L., Boden, P. R., and Treherne, J. M. (1990). Glucose-induced excitation of hypothalamic neurones is mediated by ATP-sensitive $\mathrm{K}^{+}$ channels. Pfugers Arch. 415, 479-483. doi: 10.1007/BF00373626 level of the hindbrain, given the response of the catecholamine neurons to glucoprivic agents. In addition activation of these hindbrain glucose sensors initiates feeding and corticosterone responses through hypothalamic projections. On the other hand when glucose levels fall rapidly, the threat to the brain is more severe and hypothalamic glucose sensors are fully capable of restoring euglycemia.

Based on our data we hypothesize that even under slowonset hypoglycemia the $\mathrm{VMH}$ glucose sensors integrate the information and potentially enhance the CRR during energy deficit. That is, VMH nNOS (glutamatergic?) GI neurons may be important in setting the gain of the response to compensate for the current energetic status of the body. In particular, the degree of activation of VMH nNOS GI neurons in low glucose is closely coupled to the magnitude of the hormonal CRR. These GI neurons are particularly sensitive to oxidative stress and enhancing antioxidant defenses during either $\mathrm{RH}$ or diabetes is sufficient to preserve the CRR. Further work needs to be done in order to determine whether this strategy will be effective when HAAF occurs during diabetes. Interestingly, enhancing $\mathrm{VMH}$ antioxidant defenses appears to be very important for restoring glucagon responses during early diabetes as well as aiding in glycemic management. In the future it would be interesting to determine whether GI neurons are playing a role in both of these VMH functions. It will also be important to determine whether the effects of thioredoxin persist in type 2 diabetes mellitus or in other models of type 1 diabetes. Finally, the PFH orexin-GI neurons may play a role in hypoglycemia awareness by coupling arousal and behavioral responses during hypoglycemia.

\section{AUTHOR CONTRIBUTIONS}

CZ, ST, BK, and CG wrote portions of the first draft with $\mathrm{CZ}$ making the greatest contribution. VR revised the first draft critically for important intellectual content, wrote the Perspectives section and generated the final draft of the manuscript.

\section{ACKNOWLEDGMENTS}

This work was supported in part by Juvenile Diabetes Research Foundation Grant \# 2-SRA-2014-269-M-R and 3-SRA-2017-488S-B, and by NIH-1R01DK103676-01A1. 
Borg, M. A., Sherwin, R. S., Borg, W. P., Tamborlane, W. V., and Shulman, G. I. (1997). Local ventromedial hypothalamus glucose perfusion blocks counterregulation during systemic hypoglycemia in awake rats. J. Clin. Invest. 99, 361-365. doi: 10.1172/JCI119165

Borg, W. P., During, M. J., Sherwin, R. S., Borg, M. A., Brines, M. L., and Shulman, G. I. (1994). Ventromedial hypothalamic lesions in rats suppress counterregulatory responses to hypoglycemia. J. Clin. Invest. 93, 1677-1682. doi: 10.1172/JCI117150

Borg, W. P., Sherwin, R. S., During, M. J., Borg, M. A., and Shulman, G. I. (1995). Local ventromedial hypothalamus glucopenia triggers counterregulatory hormone release. Diabetes 44, 180-184. doi: 10.2337/diab.44.2.180

Bottini, P., Boschetti, E., Pampanelli, S., Ciofetta, M., Del Sindaco, P., Scionti, L., et al. (1997). Contribution of autonomic neuropathy to reduced plasma adrenaline responses to hypoglycemia in IDDM: evidence for a nonselective defect. Diabetes 46, 814-823. doi: 10.2337/diab.46.5.814

Burdakov, D., Gerasimenko, O., and Verkhratsky, A. (2005). Physiological changes in glucose differentially modulate the excitability of hypothalamic melaninconcentrating hormone and orexin neurons in situ. J. Neurosci. 25, 2429-2433. doi: 10.1523/JNEUROSCI.4925-04.2005

Canabal, D. D., Potian, J. G., Duran, R. G., McArdle, J. J., and Routh, V. H. (2007a). Hyperglycemia impairs glucose and insulin regulation of nitric oxide production in glucose-inhibited neurons in the ventromedial hypothalamus. Am. J. Physiol. Regul. Integr. Comp. Physiol. 293, R592-R600. doi: 10.1152/ajpregu.00207.2007

Canabal, D. D., Song, Z., Potian, J. G., Beuve, A., McArdle, J. J., and Routh, V. H. (2007b). Glucose, insulin and leptin signaling pathways modulate nitric oxide (NO) synthesis in glucose-inhibited (GI) neurons in the ventromedial hypothalamus (VMH). Am. J. Physiol. Regul. Integr. Comp. Physiol. 292, R1418R1428. doi: 10.1152/ajpregu.00216.2006

Cardoso, S., Santos, M. S., Seiça, R., and Moreira, P. I. (2010). Cortical and hippocampal mitochondria bioenergetics and oxidative status during hyperglycemia and/or insulin-induced hypoglycemia. Biochim. Biophys. Acta 1802, 942-951. doi: 10.1016/j.bbadis.2010.07.001

Chachlaki, K., Malone, S. A., Qualls-Creekmore, E., Hrabovszky, E., Münzberg, H., Giacobini, P., et al. (2017). Phenotyping of nNOS neurons in the postnatal and adult female mouse hypothalamus. J. Comp. Neurol. 525, 3177-3189. doi: $10.1002 / \mathrm{cne} .24257$

Chan, O., Paranjape, S. A., Horblitt, A., Zhu, W., and Sherwin, R. S. (2013). Lactateinduced release of GABA in the ventromedial hypothalamus contributes to counterregulatory failure in recurrent hypoglycemia and diabetes. Diabetes 62, 4239-4246. doi: 10.2337/db13-0770

Colombani, A. L., Carneiro, L., Benani, A., Galinier, A., Jaillard, T., Duparc, T., et al. (2009). Enhanced hypothalamic glucose sensing in obesity: alteration of redox signaling. Diabetes 58, 2189-2197. doi: 10.2337/db09-0110

Coutinho, E. A., Okamoto, S., Ishikawa, A. W., Yokota, S., Wada, N., Hirabayashi, T., et al. (2017). Activation of SF1 neurons in the ventromedial hypothalamus by DREADD technology increases insulin sensitivity in peripheral tissues. Diabetes 66, 2372-2386. doi: 10.2337/db16-1344

Cryer, P. E. (1981). Glucose counterregulation in man. Diabetes 30, 261-264. doi: $10.2337 /$ diab.30.3.261

Cryer, P. E. (2005). Mechanisms of hypoglycemia-associated autonomic failure and its component syndromes in diabetes. Diabetes 54, 3592-3601. doi: $10.2337 /$ diabetes.54.12.3592

Cryer, P. E. (2013). Mechanisms of hypoglycemia-associated autonomic failure in diabetes. N. Engl. J. Med. 369, 362-372. doi: 10.1056/NEJMra1215228

Cryer, P. E., Davis, S. N., and Shamoon, H. (2003). Hypoglycemia in diabetes. Diabetes Care 26, 1902-1912. doi: 10.2337/diacare.26.6.1902

Dejanovic, B., and Schwarz, G. (2014). Neuronal nitric oxide synthase-dependent s-nitrosylation of gephyrin regulates gephyrin clustering at GABAergic synapses. J. Neurosci. 34, 7763-7768. doi: 10.1523/JNEUROSCI.0531-14.2014

Diggs-Andrews, K. A., Zhang, X., Song, Z., Daphna-Iken, D., Routh, V. H., and Fisher, S. J. (2010). Brain insulin action regulates hypothalamic glucose sensing and the counterregulatory response to hypoglycemia. Diabetes 59, 2271-2280. doi: $10.2337 / \mathrm{db} 10-0401$

Donovan, C. M., Hamilton-Wessler, M., Halter, J. B., and Bergman, R. N. (1994). Primacy of liver glucosensors in the sympathetic response to progressive hypoglycemia. Proc. Natl. Acad. Sci. U.S.A. 91, 2863-2867. doi: 10.1073/pnas.91.7.2863
Donovan, C. M., and Watts, A. G. (2014). Peripheral and central glucose sensing in hypoglycemic detection. Physiology 29, 314-324. doi: 10.1152/physiol.00069.2013

Dunn-Meynell, A. A., Routh, V. H., Kang, L., Gaspers, L., and Levin, B. E. (2002). Glucokinase is the likely mediator of glucosensing in both glucose-excited and glucose-inhibited central neurons. Diabetes 51, 2056-2065. doi: 10.2337/diabetes.51.7.2056

Dunn-Meynell, A. A., Sanders, N. M., Compton, D., Becker, T. C., Eiki, J., Zhang, B. B., et al. (2009). Relationship among brain and blood glucose levels and spontaneous and glucoprivic feeding. J. Neurosci. 29, 7015-7022. doi: 10.1523/JNEUROSCI.0334-09.2009

Edelmann, M., Wolfe, C., Scordalakes, E. M., Rissman, E. F., and Tobet, S. (2007). Neuronal nitric oxide synthase and calbindin delineate sex differences in the developing hypothalamus and preoptic area. Dev. Neurobiol. 67, 1371-1381. doi: 10.1002/dneu.20507

Fan, X., Chan, O., Ding, Y., Zhu, W., Mastaitis, J., and Sherwin, R. (2015). Reduction in SGLT1 mRNA expression in the ventromedial hypothalamus improves the counterregulatory responses to hypoglycemia in recurrently hypoglycemic and diabetic rats. Diabetes 64, 3564-3572. doi: $10.2337 / \mathrm{db} 15-0022$

Fioramonti, X., Deak, A., Deshpande, S., Carneiro, L., Zhou, C., Sayed, N., et al. (2013). Hypothalamic S-nitrosylation contributes to the counter-regulatory response impairment following recurrent hypoglycemia. PLOS ONE 8:e68709. doi: 10.1371/journal.pone.0068709

Fioramonti, X., Marsollier, N., Song, Z., Fakira, K. A., Patel, R. M., Brown, S., et al. (2010). Ventromedial hypothalamic nitric oxide production is necessary for hypoglycemia detection and counterregulation. Diabetes 59, 519-528. doi: $10.2337 / \mathrm{db} 09-0421$

Frayling, C., Britton, R., and Dale, N. (2011). ATP-mediated glucosensing by hypothalamic tanycytes. J. Physiol. 589, 2275-2286. doi: 10.1113/jphysiol.2010.202051

Fujita, S., Bohland, M., Sanchez-Watts, G., Watts, A. G., and Donovan, C. M. (2007). Hypoglycemic detection at the portal vein is mediated by capsaicinsensitive primary sensory neurons. Am. J. Physiol. Endocrinol. Metab. 293, E96-E101. doi: 10.1152/ajpendo.00415.2006

Hevener, A. L., Bergman, R. N., and Donovan, C. M. (2000). Portal afferents are critical for the sympathoadrenal response to hypoglycemia. Diabetes $49,8-12$. doi: $10.2337 /$ diabetes.49.1.8

Israelian, Z., Szoke, E., Woerle, J., Bokhari, S., Schorr, M., Schwenke, D. C., et al. (2006). Multiple defects in counterregulation of hypoglycemia in modestly advanced type 2 diabetes mellitus. Metab. Clin. Exp. 55, 593-598. doi: 10.1016/j.metabol.2005.11.013

Jaffrey, S. R., Erdjument-Bromage, H., Ferris, C. D., Tempst, P., and Snyder, S. H. (2001). Protein S-nitrosylation: a physiological signal for neuronal nitric oxide. Nat. Cell Biol. 3, 193-197. doi: 10.1038/35055104

Jokiaho, A. J., Donovan, C. M., and Watts, A. G. (2014). The rate of fall of blood glucose determines the necessity of forebrain-projecting catecholaminergic neurons for male rat sympathoadrenal responses. Diabetes 63, 2854-2865. doi: $10.2337 / \mathrm{db} 13-1753$

Kang, L., Dunn-Meynell, A. A., Routh, V. H., Gaspers, L. D., Nagata, Y., Nishimura, T., et al. (2006). Glucokinase is a critical regulator of ventromedial hypothalamic neuronal glucosensing. Diabetes 55, 412-420. doi: $10.2337 /$ diabetes.55.02.06.db05-1229

Kang, L., Sanders, N. M., Dunn-Meynell, A. A., Gaspers, L. D., Routh, V. H., Thomas, A. P., et al. (2008). Prior hypoglycemia enhances glucose responsiveness in some ventromedial hypothalamic glucosensing neurons. Am. J. Physiol. Regul. Integr. Comp. Physiol. 294, R784-R792. doi: 10.1152/ajpregu.00645.2007

Korim, W. S., Llewellyn-Smith, I. J., and Verberne, A. J. (2016). Activation of medulla-projecting perifornical neurons modulates the adrenal sympathetic response to hypoglycemia: involvement of orexin type 2 (ox2-r) receptors. Endocrinology 157, 810-819. doi: 10.1210/en.2015-1712

Kovatchev, B. P., Clarke, W. L., Breton, M., Brayman, K., and McCall, A. (2005). Quantifying temporal glucose variability in diabetes via continuous glucose monitoring: mathematical methods and clinical application. Diabetes Technol. Ther. 7, 849-862. doi: 10.1089/dia.2005.7.849

Levin, B. E. (2000). Glucose-regulated dopamine release from substantia nigra neurons. Brain Res. 874, 158-164. doi: 10.1016/S0006-8993(00)02573-7 
Li, A. J., Wang, Q., Davis, H., Wang, R., and Ritter, S. (2015a). OrexinA enhances feeding in male rats by activating hindbrain catecholamine neurons. Am. J. Physiol. Regul. Integr. Comp. Physiol. 309, R358-R367. doi: 10.1152/ajpregu.00065.2015

Li, A. J., Wang, Q., Elsarelli, M. M., Brown, R. L., and Ritter, S. (2015b). Hindbrain catecholamine neurons activate orexin neurons during systemic glucoprivation in male rats. Endocrinology. 156, 2807-2820. doi: 10.1210/en.2015 $-1138$

Li, A. J., Wang, Q., and Ritter, S. (2017). Selective pharmacogenetic activation of catecholamine subgroups in the ventrolateral medulla elicits key glucoregulatory responses. Endocrinology 159, 341-355. doi: 10.1210/en.2017-00630

Martins, L., Seoane-Collazo, P., Contreras, C., González-García, I., MartínezSánchez, N., González, F., et al. (2016). A functional link between AMPK and orexin mediates the effect of BMP8B on energy balance. Cell Rep. 16, 2231-2242. doi: 10.1016/j.celrep.2016.07.045

Marty, N., Dallaporta, M., Foretz, M., Emery, M., Tarussio, D., Bady, I., et al. (2005). Regulation of glucagon secretion by glucose transporter type 2 (glut2) and astrocyte-dependent glucose sensors. J. Clin. Invest. 115, 3545-3553. doi: 10.1172/JCI26309

Matveyenko, A. V., Bohland, M., Saberi, M., and Donovan, C. M. (2007). Portal vein hypoglycemia is essential for full induction of hypoglycemia-associated autonomic failure with slow-onset hypoglycemia. Am. J. Physiol. Endocrinol. Metab. 293, E857-E864. doi: 10.1152/ajpendo.00283.2007

McCrimmon, R. J., Shaw, M., Fan, X., Cheng, H., Ding, Y., Vella, M. C., et al. (2008). Key role for AMP-activated protein kinase in the ventromedial hypothalamus in regulating counterregulatory hormone responses to acute hypoglycemia. Diabetes 57, 444-450. doi: 10.2337/db07-0837

McCrimmon, R. J., Song, Z., Cheng, H., McNay, E. C., Weikart-Yeckel, C., Fan, X., et al. (2006). Corticotrophin-releasing factor receptors within the ventromedial hypothalamus regulate hypoglycemia- induced hormonal counterregulation. J. Clin. Invest. 116, 1723-1730. doi: 10.1172/JCI27775

Melnick, I. V., Price, C. J., and Colmers, W. F. (2011). Glucosensing in parvocellular neurons of the rat hypothalamic paraventricular nucleus. Eur. J. Neurosci. 34, 272-282. doi: 10.1111/j.1460-9568.2011.07742.x

Mitrakou, A., Ryan, C., Veneman, T., Mokan, M., Jenssen, T., Kiss, I., et al. (1991). Hierarchy of glycemic thresholds for counterregulatory hormone secretion, symptoms, and cerebral dysfunction. Am. J. Physiol. Endocrinol. Metab. 260, E67-E74. doi: 10.1152/ajpendo.1991.260.1.E67

Murphy, B. A., Fakira, K. A., Song, Z., Beuve, A., and Routh, V. H. (2009a). AMP-activated protein kinase (AMPK) and nitric oxide (NO) regulate the glucose sensitivity of ventromedial hypothalamic (VMH) glucoseinhibited (GI) neurons. Am. J. Physiol. Cell Physiol. 297, C750-C758. doi: 10.1152/ajpcell.00127.2009

Murphy, B. A., Fioramonti, X., Jochnowitz, N., Fakira, K., Gagen, K., Contie, S., et al. (2009b). Fasting enhances the response of arcuate neuropeptide $Y$ (NPY)-glucose-inhibited (GI) neurons to decreased extracellular glucose. Am. J. Physiol. Cell Physiol. 296, 746-756. doi: 10.1152/ajpcell.00641.2008

Nordberg, J., and Arnér, E. S. (2001). Reactive oxygen species, antioxidants, and the mammalian thioredoxin system. Free Radic. Biol. Med. 31, 1287-1312. doi: 10.1016/S0891-5849(01)00724-9

Oomura, Y., Kimura, K., Ooyama, H., Maeo, T., Iki, M., and Kuniyoshi, N. (1964). Reciprocal activities of the ventromedial and lateral hypothalamic area of cats. Science 143, 484-485. doi: 10.1126/science.143.3605.484

Otlivanchik, O., Le Foll, C., and Levin, B. E. (2015). Perifornical hypothalamic orexin and serotonin modulate the counterregulatory response to hypoglycemic and glucoprivic stimuli. Diabetes 64, 226-235. doi: $10.2337 / \mathrm{db} 14-0671$

Otlivanchik, O., Sanders, N. M., Dunn-Meynell, A., and Levin, B. E. (2016). Orexin signaling is necessary for hypoglycemia-induced prevention of conditioned place preference. Am. J. Physiol. Regul. Integr. Comp. Physiol. 310, R66-R73. doi: 10.1152/ajpregu.00066.2015

Oyer, D. (2013). The science of hypoglycemia in patients with diabetes. Curr. Diabetes Rev. 9, 195-208. doi: 10.2174/15733998113099990059

Ritter, R. C., Slusser, P. G., and Stone, S. (1981). Glucoreceptors controlling feeding and blood glucose: location in the hindbrain. Science 213, 451-452. doi: $10.1126 /$ science. 6264602
Ritter, S., Bugarith, K., and Dinh, T. T. (2001). Immunotoxic destruction of distinct catecholamine subgroups produces selective impairment of glucoregulatory responses and neuronal activation. J. Comp. Neurol. 432, 197-216. doi: 10.1002/cne.1097

Ritter, S., Dinh, T. T., and Li, A. J. (2006). Hindbrain catecholamine neurons control multiple glucoregulatory responses. Physiol. Behav. 89, 490-500. doi: 10.1016/j.physbeh.2006.05.036

Ritter, S., Li, A. J., Wang, Q., and Dinh, T. T. (2011). Minireview: the value of looking backward: the essential role of the hindbrain in counterregulatory responses to glucose deficit. Endocrinology 152, 4019-4032. doi: 10.1210/en.2010-1458

Ritter, S., Llewellyn-Smith, I., and Dinh, T. T. (1998). Subgroups of hindbrain catecholamine neurons are selectively activated by 2deoxy-D-glucose induced metabolic challenge. Brain Res. 805, 41-54. doi: 10.1016/S0006-8993(98)00655-6

Routh, V. H. (2003). Glucosensing neurons in the ventromedial hypothalamic nucleus (VMN) and hypoglycemia-associated autonomic failure (HAAF). Diabetes Metab. Res. Rev. 19, 348-56. doi: 10.1002/dmrr.404

Routh, V. H., Donovan, C. M., and Ritter, S. (2012). 2. Hypoglycemia Detection. Transl. Endocrinol. Metabo. 3, 47-87. doi: 10.1210/TEAM.9781936704200.ch2

Saberi, M., Bohland, M., and Donovan, C. M. (2008). The locus for hypoglycemic detection shifts with the rate of fall in glycemia: the role of portal-superior mesenteric vein glucose sensing. Diabetes 57, 1380-1386. doi: $10.2337 / \mathrm{db} 07-1528$

Sayed, N., Baskaran, P., Ma, X., van den Akker, F., and Beuve, A. (2007). Desensitization of soluble guanylyl cyclase, the NO receptor, by S-nitrosylation. Proc. Nail. Acad. Sci. U.S.A. 104, 12312-12317. doi: 10.1073/pnas.0703944104

Segel, S. A., Paramore, D. S., and Cryer, P. E. (2002). Hypoglycemia-associated autonomic failure in advanced type 2 diabetes. Diabetes 51, 724-733. doi: 10.2337/diabetes.51.3.724

Sheng, Z., Santiago, A. M., Thomas, M. P., and Routh, V. H. (2014). Metabolic regulation of lateral hypothalamic glucose-inhibited orexin neurons may influence midbrain reward neurocircuitry. Mol. Cell. Neurosci. 62, 30-41. doi: $10.1016 /$ j.men.2014.08.001

Siafarikas, A., Johnston, R. J., Bulsara, M. K., O'Leary, P., Jones, T. W., and Davis, E. A. (2012). Early loss of the glucagon response to hypoglycemia in adolescents with type 1 diabetes. Diabetes Care 35, 1757-1762. doi: 10.2337/dc11-2010

Song, Z., Levin, B. E., McArdle, J. J., Bakhos, N., and Routh, V. H. (2001). Convergence of pre- and postsynaptic influences on glucosensing neurons in the ventromedial hypothalamic nucleus. Diabetes 50, 2673-2681. doi: $10.2337 /$ diabetes.50.12.2673

Song, Z., and Routh, V. H. (2006). Recurrent hypoglycemia reduces the glucose sensitivity of glucose-inhibited neurons in the ventromedial hypothalamus nucleus (VMN). Am. J. Physiol. Regul. Integr. Comp. Physiol. 291, R1283R1287. doi: 10.1152/ajpregu.00148.2006

Steffens, A. B., Scheurink, A. J., Luiten, P. G., and Bohus, B. (1988). Hypothalamic food intake regulating areas are involved in the homeostasis of blood glucose and plasma FFA levels. Physiol. Behav. 44, 581-589. doi: 10.1016/0031-9384(88)90322-8

Stoyanovsky, D. A., Tyurina, Y. Y., Tyurin, V. A., Anand, D., Mandavia, D. N., Gius, D., et al. (2005). Thioredoxin and lipoic acid catalyze the denitrosation of low molecular weight and protein s-nitrosothiols. J. Am. Chem. Soc. 127, 15815-15823. doi: 10.1021/ja0529135

Sundvik, M., and Panula, P. (2015). Interactions of the orexin/hypocretin neurones and the histaminergic system. Acta Physiologica. 213, 321-333. doi: 10.1111/apha. 12432

Toda, C., Kim, J. D., Impellizzeri, D., Cuzzocrea, S., Liu, Z. W., and Diano, S. (2016). UCP2 regulates mitochondrial fission and ventromedial nucleus control of glucose responsiveness. Cell 164, 872-883. doi: 10.1016/j.cell.2016.02.010

Tong, Q., Ye, C., McCrimmon, R. J., Dhillon, H., Choi, B., and Kramer, M. D., et al. (2007). Synaptic glutamate release by ventromedial hypothalamic neurons is part of the neurocircuitry that prevents hypoglycemia. Cell Metab. 5, 383-393. doi: 10.1016/j.cmet.2007.04.001

Towler, D. A., Havlin, C. E., Craft, S., and Cryer, P. (1993). Mechanism of awareness of hypoglycemia: perception of neurogenic (predominantly cholinergic) rather than neuroglycopenic symptoms. Diabetes 42, 1791-1798. doi: $10.2337 /$ diab.42.12.1791 
Zhou, C., and Routh, V. H. (2017). Thioredoxin-1 overexpression in the ventromedial nucleus of the hypothalamus (VMH) preserves the counterregulatory response to hypoglycemia during type 1 diabetes mellitus in male rats. Diabetes 67, 120-130. doi: 10.2337/db17-0930

Zhou, L., Podolsky, N., Sang, Z., Ding, Y., Fan, X., Tong, Q., et al. (2010). the medial amygdalar nucleus: a novel glucose-sensing region that modulates the counterregulatory response to hypoglycemia. Diabetes 59, 2646-2652. doi: 10.2337/db09-0995

Ziegler, D. R., Cullinan, W. E., and Herman, J. P. (2002). Distribution of vesicular glutamate transporter mRNA in rat hypothalamus. J. Comp. Neurol. 448, 217-229. doi: 10.1002/cne.10257
Conflict of Interest Statement: The authors declare that the research was conducted in the absence of any commercial or financial relationships that could be construed as a potential conflict of interest.

Copyright (C) 2018 Zhou, Teegala, Khan, Gonzalez and Routh. This is an open-access article distributed under the terms of the Creative Commons Attribution License (CC $B Y)$. The use, distribution or reproduction in other forums is permitted, provided the original author(s) and the copyright owner are credited and that the original publication in this journal is cited, in accordance with accepted academic practice. No use, distribution or reproduction is permitted which does not comply with these terms. 